\title{
Examples of discriminating the downward depth and downward timing of the velocity string in the water-producing gas well
}

\author{
Jing Yang ${ }^{1}$, Minhao Guo ${ }^{2}$, Le Yan ${ }^{1}$, Xin Fan $^{1}$, Haiyang Wang ${ }^{1, *}$, and Desheng Zhou ${ }^{1,3}$ \\ ${ }^{1}$ College of Petroleum Engineering, Xi' an Shiyou University, Xi'an, 710065, China \\ ${ }^{2}$ The College of Life Sciences, Northwest University, Xi'an, 710069, China \\ ${ }^{3}$ Engineering Research Center of Development and Management for Low to Extra-Low Permeability Oil \& Gas Reservoirs in West \\ China, Ministry of Education, Xi'an Shiyou University, Xi'an, 710065, Shaanxi, China
}

\begin{abstract}
The problem of bottom hole effusion is an important reason for the reduction and even shutdown of natural gas wells. Downward velocity string is an important drainage gas recovery process, which can improve the flow rate of gas and discharge more liquid from the wellhead. However, the depth and timing of the velocity string is a technical problem that has been difficult to solve by field engineers. To solve this problem, this paper designs a method to select the depth and timing of the velocity string in the case of highly deviated wells and applies this method to Well X6-2 and Well X2-1 of PCOC in Ordos Basin, China. The optimization results show that when the wellhead pressure is $6.26 \mathrm{MPa}$, Well X6-2 should lower the 21.71 in. or 2.375-1.995 in. velocity string to $3337.9 \mathrm{~m}$ before the formation pressure decays to $8.800 \mathrm{MPa}$, which is most conducive to improve the liquid carrying capacity of gas wells. When the wellhead pressure is $4 \mathrm{MPa}$, Well X2-1 should lower 2-1.71 in. velocity string to $3401.3 \mathrm{~m}$ before the formation pressure decays to $5.800 \mathrm{MPa}$, or lower 2.375-1.995 in. velocity string to $3401.3 \mathrm{~m}$ before the formation pressure decays to $5.900 \mathrm{MPa}$.
\end{abstract}

\section{Introduction}

Natural gas is the main energy source for the development of the national economy. However, natural gas extraction is always accompanied by liquids from condensate oil and water. With the continuous production of gas wells, the energy of gas wells is gradually insufficient. These liquids will gradually form fluid accumulation at the bottom of the well, causing the production of gas wells to drop sharply or even stop production..$^{[1]}$

To solve the problem of fluid accumulation at the bottom of the well and increase the production of gas wells, the oilfield site will regularly conduct drainage gas production processes to drain the fluid accumulation in the wellbore. There are several types of drainage gas recovery processes commonly used: velocity string drainage gas recovery technology, foam drainage gas recovery technology, gas lift drainage gas recovery technology, electric submersible pump drainage gas recovery technology, and jet pump drainage gas recovery technology. ${ }^{[2]}$

Among them, lowering the velocity string to the bottom of the well is an important drainage gas production process. Generally, the larger the diameter of the tubing, the higher the output of the gas well. However, the tubing with a larger inner diameter may not be able to continue to meet the continuous liquidcarrying capacity of the gas in the wellbore in the late stage of the gas well. At this time, you can replace the tubing with a smaller size to enhance the gas flow rate and its liquid-carrying capacity, thereby discharging the liquid from the well. It is called the velocity string drainage gas recovery technology. ${ }^{[3,4]}$

Zhou J et al. (2013) developed a suspension and sealing device for velocity string operation, which can realize the pre-placement of slips before the velocity string is lowered, which solves the suspension, sealing, and shearing problems of the velocity string under pressure. ${ }^{[5]} \mathrm{Xie} \mathrm{Y}$ et al. (2013) in response to the increasing number of low-yield and low-efficiency wells in the Zizhou gas field, carried out research and field tests on velocity string drainage gas production technology, which provided new technical means for improving the development effect of low-yield and lowefficiency wells. ${ }^{[6]}$ Zhao B et al. (2013) analyzed the timing of the velocity string from two aspects of economy and technology to ensure that the cost can be recovered after the velocity string is used for production, and the role of the velocity string for drainage and gas recovery can be fully utilized. ${ }^{[7]}$ Wuchao $\mathrm{W} \mathrm{U}$ et al. (2015) applied the critical liquid carrying model to study the downward time of the velocity string and believed that when the daily production began to be lower than the critical liquid carrying flow rate in a large range, it was the best time to lower the velocity string ${ }^{[8]}$ Binbin $\mathrm{Z}$ et al. (2018) calculated the location of the most prone to fluid accumulation in horizontal wells by using the

\footnotetext{
Corresponding author: 244006468@qq.com
} 
straight well section model and the inclined well section model, and clarified the optimal down-entry depth of the velocity string, which solved the problem that the velocity string cannot enter under pressure in highly deviated wells. ${ }^{[9]}$

However, it can be seen from the above literature that the depth and timing of the velocity string have always been technical problems that are difficult for field engineers to solve, and the main reliance is still on empirical judgment. In response to this problem, this article first designs a method for identifying the depth and timing of the velocity string in the case of highly deviated wells; then this method is applied to Well X6-2 and Well X2-1 in PCOC. This identification method can provide a reference for oilfield engineers.

\section{Basic data of the well and design process}

This article is aimed at two highly inclined horizontal wells: Well X6-2 and Well X2-1 in PCOC, Ordos Basin, China. The basic data of the well is shown in Table 1:

Table 1. The basic data of the well.

\begin{tabular}{|c|c|c|}
\hline $\begin{array}{c}\text { Basic parameters } \\
\text { Classification of } \\
\text { well }\end{array}$ & Well X6-2 & Well X2-1 \\
\hline Wellbore radius & $0.108 \mathrm{~m}$ & $0.108 \mathrm{~m}$ \\
\hline $\begin{array}{c}\text { Vertical well } \\
\text { section depth } \\
\text { sounding }\end{array}$ & $0-2066 \mathrm{~m}$ & $0-1474.1 \mathrm{~m}$ \\
\hline $\begin{array}{c}\text { Inclined well } \\
\text { section depth } \\
\text { sounding }\end{array}$ & $2066-3337.9 \mathrm{~m}$ & $1474.1-3401.3 \mathrm{~m}$ \\
\hline $\begin{array}{c}\text { Horizontal } \\
\text { section length }\end{array}$ & $912.4 \mathrm{~m}$ & $1776 \mathrm{~m}$ \\
\hline $\begin{array}{c}\text { Casing setting } \\
\text { depth }\end{array}$ & $3337.9 \mathrm{~m}$ & $3401.3 \mathrm{~m}$ \\
\hline $\begin{array}{c}\text { Tubing setting } \\
\text { depth }\end{array}$ & $3324 \mathrm{~m}$ & $3306.7 \mathrm{~m}$ \\
\hline $\begin{array}{c}\text { Initial formation } \\
\text { pressure }\end{array}$ & $26.5 \mathrm{MPa}$ & $22.7 \mathrm{MPa}$ \\
\hline
\end{tabular}

The flow chart design of the downward depth and downward timing of the velocity string is shown in Fig. 1 .

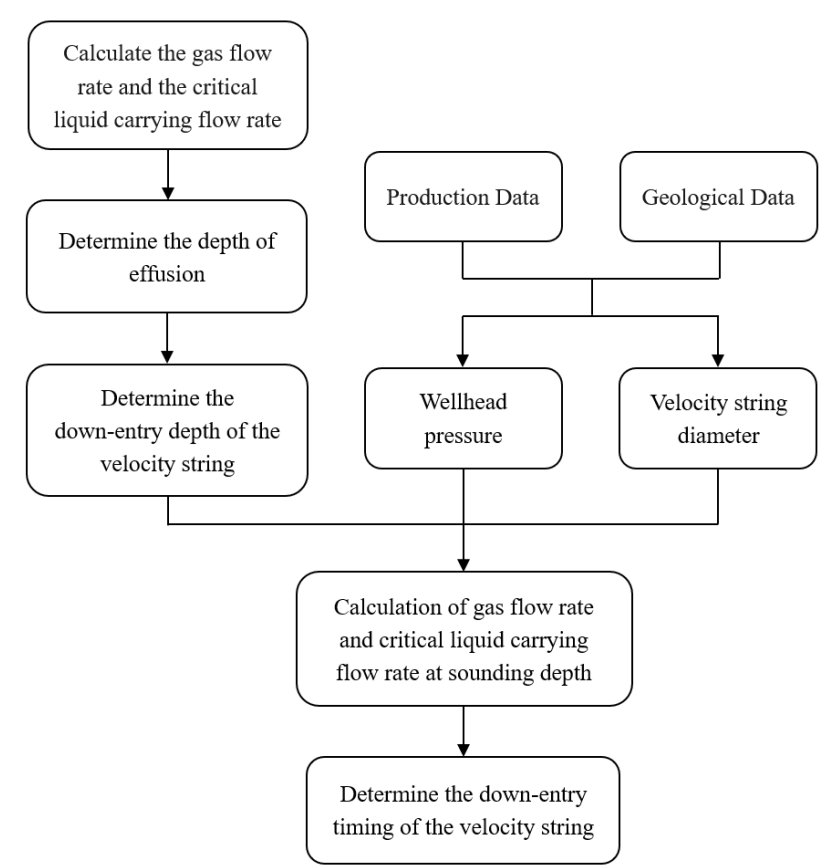

Fig. 1. The flow chart design of down-entry depth and downentry timing of velocity string

\section{Determination of the downward depth of velocity string}

(1) Calculation of actual gas flow rate: Gray model is used to calculate the actual gas flow rate in vertical and inclined well sections. ${ }^{[10]}$

$$
\frac{d p}{d z}=\frac{f \rho_{n} V_{m}^{2}}{2 d}+\rho_{m} g-\rho_{n}{ }^{2} V_{m}{ }^{2} \frac{d}{d z}\left(\frac{1}{\rho_{n}}\right)
$$

Where $f$, is friction resistance coefficient; $\rho_{n}, \mathrm{~kg} / \mathrm{m}^{3}$, is natural gas density; $\rho_{m}, \mathrm{~kg} / \mathrm{m}^{3}$, is mixture density; $V_{m}$, $\mathrm{m} / \mathrm{s}$, is the apparent velocity of gas-liquid mixture; $d, \mathrm{~m}$, is wellbore radius; and $g, \mathrm{~m}^{2} / \mathrm{s}$, is the acceleration of gravity.

Combining the formation pressure and the daily production under the conditions of formation temperature, the length of the horizontal section, and the radius of the wellbore, the gas flow rate in the horizontal section is converted.

(2) Calculation of critical liquid-carrying flow rate: In the vertical well section, the commonly used critical liquid-carrying flow rate models include Turner model, Coleman model, and Li Min model. Based on the Turner model, Fernando et al. considered the influence of inclination angle on the critical liquid carrying flow rate and established the Fernando model. Through comparative calculation, the Turner model and Fernando model are selected to calculate the critical liquid carrying flow rate of vertical and inclined sections of Well X6-2 and Well X2-1.

Through calculation, it is found that the actual flow rate of gas in each part of the wellbore in the vertical section of Well X6-2 and Well X2-1 is higher than the critical liquid carrying flow rate, so there is no fluid accumulation in the vertical section. The actual gas flow 
rate of Well X6-2 at $3337.9 \mathrm{~m}$ is lower than the critical liquid carrying flow rate, and the gas flow rates above $3324 \mathrm{~m}$ are higher than the critical liquid carrying flow rate. Therefore, there must be effusion at the bottom of the inclined section of Well X6-2. The actual gas flow tare of Well X2-1 at $3375.7 \mathrm{~m}$ and $3401.3 \mathrm{~m}$ are lower than the critical liquid carrying flow rates, while the gas flow rates above $3278.9 \mathrm{~m}$ are higher than the critical liquid carrying flow rates. Therefore, there must be effusion at the bottom of the inclined section of Well $\mathrm{X} 2-1$.

It is calculated that the liquid flow rate in the horizontal section of Well X6-2 and Well X2-1 is much smaller than the gas flow rate. According to the Mandhane flow pattern diagram of the horizontal wellbore, it can be concluded that the flow pattern in the horizontal wellbore of the two wells is stratified flow. It indicates that there is no effusion in the horizontal wellbore.

In summary, no effusion was found in both horizontal and vertical sections of Well X6-2 and Well $\mathrm{X} 2-1$, and the effusion in the wellbore was found at the bottom of the inclined section. Therefore, the bottom of the inclined well section should be selected as the downward depth of the velocity string, that is, the downward depth of the velocity string in the Well X6-2 should be $3337.9 \mathrm{~m}$, and the downward depth of the velocity string in the Well X2-1 should be $3401.3 \mathrm{~m}$.

\section{Determination of the downward time of velocity string in Well X6-2}

This paper selects the outer diameter of 2 in. inner diameter $1.71 \mathrm{in}$. and outer diameter $2.375 \mathrm{in}$. inner diameter 1.995 in. two kinds of size of the velocity string for research and calculation.

By calculation, the cumulative liquid column height of Well X6-2 was $0.7 \mathrm{~m}$ from April 2018 to May 2020, and the formation pressure was reduced to $10.7 \mathrm{MPa}$. At this point, the wellhead pressure is $6.26 \mathrm{MPa}$, the daily gas production is $173378.7 \mathrm{~m}^{3} / \mathrm{d}$, the gas flow rate at the bottom of the inclined section is $0.604 \mathrm{~m} / \mathrm{s}$, and the critical liquid carrying flow rate at the bottom of the inclined section is $1.9705 \mathrm{~m} / \mathrm{s}$. The actual flow rate is much lower than the critical flow rate.

\subsection{The diameter of the velocity string is $\mathbf{2 - 1 . 7 1}$ in.}

The wellhead pressure is $6.26 \mathrm{MPa}$. At this time, the velocity string with the diameter of 2-1.71 in. is inserted into the bottom of the inclined section in Well X6-2, that is, the sounding depth of $3337.9 \mathrm{~m}$ in Well X6-2. The actual flow rate at this point is calculated to be 4.8264 $\mathrm{m} / \mathrm{s}$, the critical liquid carrying flow rate at the bottom of the inclined section is $1.6218 \mathrm{~m} / \mathrm{s}$, and the daily output is $65052.3 \mathrm{~m}^{3} / \mathrm{s}$. At this time, the actual flow rate is much higher than the critical flow rate, and the liquid carrying capacity of the gas well is enhanced and no effusion is produced.
Under the wellhead pressure of $6.26 \mathrm{MPa}$, the formation pressure is continuously reduced, and the actual flow rate and the critical liquid carrying flow rate at $3337.9 \mathrm{~m}$ are calculated. Determine the downward time of 2-1.71 in. the velocity string, and calculate the gas production. The results are shown in Table 2:

Table 2. Downward entry timing of velocity string with diameter 2-1.71 in. at wellhead pressure 6.26 MPa.

\begin{tabular}{|c|c|c|c|c|}
\hline $\begin{array}{c}\text { Formation } \\
\text { pressure } \\
/ \mathrm{MPa}\end{array}$ & $\begin{array}{c}\text { Bottom } \\
\text { hole } \\
\text { pressure } \\
/ \mathrm{MPa}\end{array}$ & $\begin{array}{c}\text { Actual } \\
\text { flow } \\
\text { rate } \\
/(\mathrm{m} / \mathrm{s})\end{array}$ & $\begin{array}{c}\text { Critical } \\
\text { flow } \\
\text { rate } \\
/(\mathrm{m} / \mathrm{s})\end{array}$ & $\begin{array}{c}\text { Production } \\
/\left(\mathrm{m}^{3} / \mathrm{d}\right)\end{array}$ \\
\hline 10.700 & 9.859 & 4.8264 & 1.6218 & 65052.3 \\
\hline 9.000 & 8.548 & 2.5973 & 1.7456 & 30732.6 \\
\hline 8.900 & 8.493 & 2.3417 & 1.7514 & 27469.4 \\
\hline 8.800 & 8.443 & 2.0507 & 1.7567 & 23850.5 \\
\hline 8.700 & 8.394 & 1.7504 & 1.7620 & 20303.9 \\
\hline
\end{tabular}

The variation of actual flow rate and critical liquid carrying flow rate with formation pressure as shown in Fig. 2:

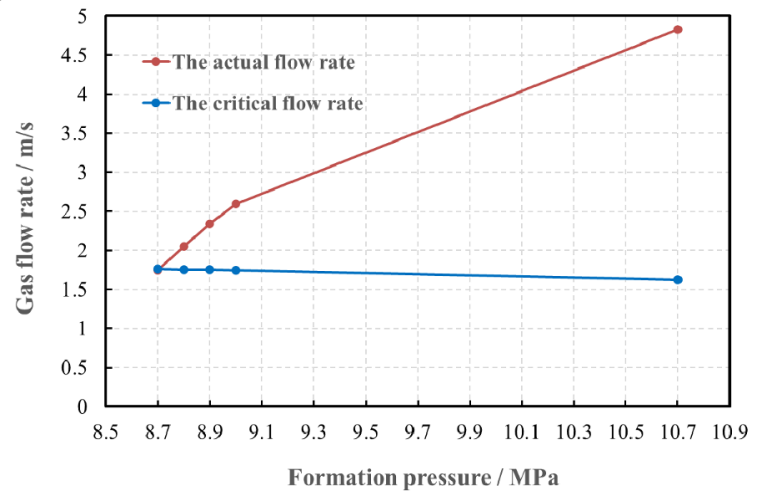

Fig. 2 The variation of the actual flow rate and critical flow rate after the diameter of 2-1.71 in. velocity string enters under the wellhead pressure of $6.26 \mathrm{MPa}$.

From Table 2 and Fig. 2, it can be seen that when the wellhead pressure is $6.26 \mathrm{MPa}$, Well X6-2 downhole enters the 2-1.71 in. velocity string to the bottom of the inclined well section. When the formation pressure decays below $8.800 \mathrm{MPa}$, the gas flow rate is lower than the critical flow rate, and the daily production is lower than $23850 \mathrm{~m}^{3} / \mathrm{d}$. At this time, the gas well begins to continue to accumulate fluid. Therefore, under the condition of wellhead pressure 6.26 MPa, Well X6-2 should enter 2-1.71 in. velocity string to the bottom of the inclined section before the formation pressure decays to $8.800 \mathrm{MPa}$. 


\subsection{The diameter of the velocity string is 2.375 - 1.995 in.}

The wellhead pressure is $6.26 \mathrm{MPa}$. At this time, the velocity string with the diameter of 2.375-1.995 in. is inserted into the bottom of the inclined section in Well $\mathrm{X} 6-2$, that is, the sounding depth is $3337.9 \mathrm{~m}$. The actual flow rate at this point is calculated to be $4.9707 \mathrm{~m} / \mathrm{s}$, the critical liquid carrying flow rate at the bottom of the inclined section is $1.6502 \mathrm{~m} / \mathrm{s}$, and the daily output is $89642.7 \mathrm{~m}^{3} / \mathrm{d}$. At this time, the actual flow rate is much higher than the critical flow rate, and the liquid carrying capacity of the gas well is enhanced and no effusion is produced.

Under the wellhead pressure of $6.26 \mathrm{MPa}$, the formation pressure is continuously reduced, and the actual flow rate and the critical liquid carrying flow rate at $3334.9 \mathrm{~m}$ are calculated. Determine the downward time of 2.375-1.995 in. the velocity string, and calculate the gas production. The results are shown in Table 3:

Table 3. Downward entry timing of velocity string with diameter 2.375-1.995 in. at wellhead pressure 6.26 MPa.

\begin{tabular}{|c|c|c|c|c|}
\hline $\begin{array}{c}\text { Formation } \\
\text { pressure } \\
/ \mathrm{MPa}\end{array}$ & $\begin{array}{c}\text { Bottom } \\
\text { hole } \\
\text { pressure } \\
/ \mathrm{MPa}\end{array}$ & $\begin{array}{c}\text { Actual } \\
\text { flow } \\
\text { rate } \\
/(\mathrm{m} / \mathrm{s})\end{array}$ & $\begin{array}{c}\text { Critical } \\
\text { flow } \\
\text { rate } \\
/(\mathrm{m} / \mathrm{s})\end{array}$ & $\begin{array}{c}\text { Production } \\
/\left(\mathrm{m}^{3} / \mathrm{d}\right)\end{array}$ \\
\hline 10.700 & 9.534 & 4.9707 & 1.6501 & 89142.7 \\
\hline 9.700 & 8.844 & 2.6617 & 1.7153 & 60901.1 \\
\hline 9.000 & 8.443 & 2.3648 & 1.7567 & 37563.3 \\
\hline 8.900 & 8.391 & 2.1602 & 1.7623 & 34110.1 \\
\hline 8.800 & 8.340 & 1.949 & 1.7678 & 30630.1 \\
\hline 8.700 & 8.394 & 1.7494 & 1.7620 & 26467.1 \\
\hline
\end{tabular}

The variation of actual flow rate and critical liquid carrying flow rate with formation pressure as shown in Fig. 3:

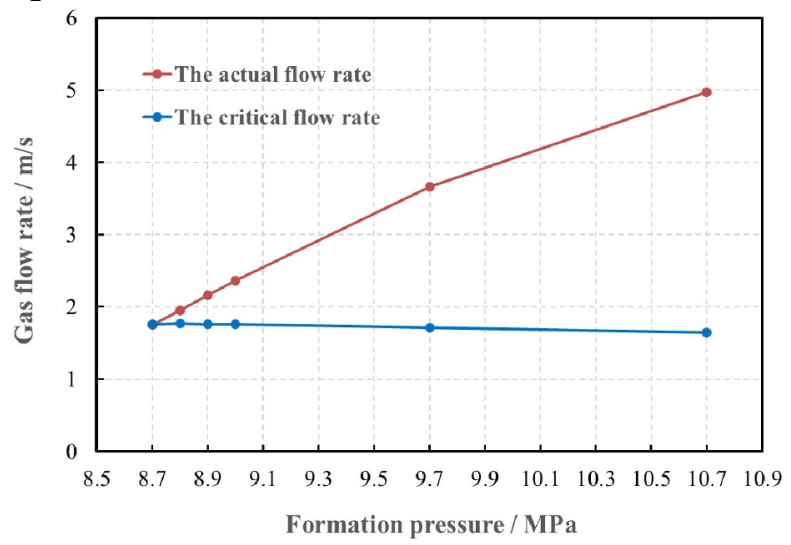

Fig. 3 The variation of the actual flow rate and critical flow rate after the diameter of 2.375-1.995 in. velocity string enters under the wellhead pressure of $6.26 \mathrm{MPa}$.
From Table 3 and Fig. 3, it can be seen that under the condition of wellhead pressure of 6.26 MPa, Well X6-2 downhole enters 2.375-1.995 in. velocity string to the bottom of the inclined well section. When the formation pressure decays below $8.800 \mathrm{MPa}$, the gas flow rate is lower than the critical flow rate, and the daily production is lower than $30630.1 \mathrm{~m}^{3} / \mathrm{d}$. At this time, the gas well begins to continue to accumulate fluid Therefore, under the condition of wellhead pressure of $6.26 \mathrm{MPa}$, Well X6-2 should enter 2.375-1.995 in. velocity string to the bottom of the inclined section before the formation pressure decays to $8.800 \mathrm{MPa}$.

\section{Determination of the downward time of velocity string in Well X2-1}

For Well X2-1, the cumulative liquid column height is calculated to be about $3 \mathrm{~m}$ from April 2018 to May 2020, and the formation pressure has decreased to $8.1 \mathrm{MPa}$. At this time, the wellhead pressure is taken as $4 \mathrm{MPa}$, and the daily production of gas wells is $137289.4 \mathrm{~m}^{3} / \mathrm{d}$. The gas flow rate at the bottom of the inclined section is $0.5715 \mathrm{~m} / \mathrm{s}$, and the critical liquid carrying flow rate at the bottom of the inclined section is $2.6208 \mathrm{~m} / \mathrm{s}$. The actual flow rate is much lower than the critical flow rate.

\subsection{The diameter of the velocity string is $\mathbf{2 - 1 . 7 1}$ in.}

The wellhead pressure is 4MPa. At this time, the velocity string with the diameter of 2-1.71 in. is inserted into the bottom of the inclined section in Well X2-1, that is, the sounding depth of $3401.3 \mathrm{~m}$ in Well X2-1. The actual flow rate at this point is $6.1023 \mathrm{~m} / \mathrm{s}$, the critical liquid carrying flow rate at the bottom of the inclined section is $2.2063 \mathrm{~m} / \mathrm{s}$, and the daily production is $66411.6 \mathrm{~m}^{3} / \mathrm{s}$. At this time, the actual flow rate is much higher than the critical flow rate, and the liquid carrying capacity of the gas well is enhanced and no effusion is produced.

Under the wellhead pressure of $4 \mathrm{MPa}$, the formation pressure is continuously reduced, and the actual flow rate and critical liquid carrying flow rate at $3401.3 \mathrm{~m}$ are calculated. Determine the downward time of 2-1.71 in. the velocity string, and calculate the gas production. The results are shown in Table 4:

Table 4. Downward entry timing of velocity string with diameter 2-1.71 in. at wellhead pressure $4 \mathrm{MPa}$.

\begin{tabular}{|c|c|c|c|c|}
\hline $\begin{array}{c}\text { Formation } \\
\text { pressure } \\
/ \mathrm{MPa}\end{array}$ & $\begin{array}{c}\text { Bottom } \\
\text { hole } \\
\text { pressure } \\
/ \mathrm{MPa}\end{array}$ & $\begin{array}{c}\text { Actual } \\
\text { flow } \\
\text { rate } \\
/(\mathrm{m} / \mathrm{s})\end{array}$ & $\begin{array}{c}\text { Critical } \\
\text { flow } \\
\text { rate } \\
/(\mathrm{m} / \mathrm{s})\end{array}$ & $\begin{array}{c}\text { Production } \\
/\left(\mathrm{m}^{3} / \mathrm{d}\right)\end{array}$ \\
\hline 8.100 & 7.351 & 6.1023 & 2.2063 & 66411.6 \\
\hline 7.100 & 6.479 & 5.1207 & 2.3535 & 49051.7 \\
\hline 6.500 & 5.992 & 4.197 & 2.4492 & 37141.3 \\
\hline
\end{tabular}




\begin{tabular}{|l|l|l|l|l|}
\hline 6.300 & 5.839 & 3.8084 & 2.4817 & 32850.4 \\
\hline 6.100 & 5.690 & 3.3717 & 2.5146 & 28379.5 \\
\hline 6.000 & 5.619 & 3.134 & 2.5307 & 26073.5 \\
\hline 5.900 & 5.549 & 2.8849 & 2.5470 & 23718.8 \\
\hline 5.800 & 5.480 & 2.6181 & 2.5632 & 21314.7 \\
\hline 5.700 & 5.413 & 2.3395 & 2.5793 & 18860.3 \\
\hline
\end{tabular}

The variation of actual flow rate and critical liquid carrying flow rate with formation pressure as shown in Fig. 4:

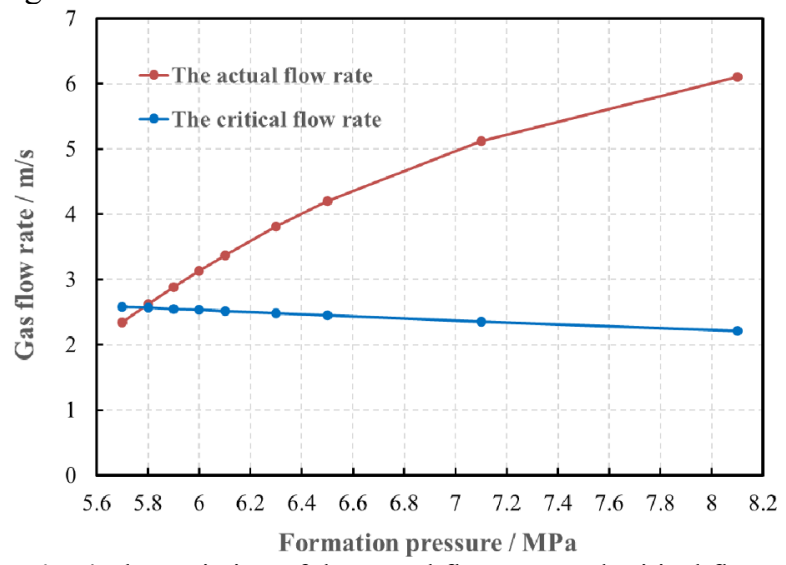

Fig. 4 The variation of the actual flow rate and critical flow rate after the diameter of 2-1.71 in. velocity string enters under the wellhead pressure of $4 \mathrm{MPa}$.

From Table 4 and Fig. 4, it can be seen that under the condition of wellhead pressure of $4 \mathrm{MPa}$, Well X2-1 downhole enters 2-1.71 in. velocity string to the bottom of the inclined well section. When the formation pressure decays below $5.800 \mathrm{MPa}$, the gas flow rate is lower than the critical flow rate, and the daily production is lower than $21314.7 \mathrm{~m}^{3} / \mathrm{d}$. At this time, the gas well begins to continue to accumulate fluid. Therefore, under the condition of wellhead pressure of $4 \mathrm{MPa}$, Well X2-1 should enter 2-1.71 in. velocity string to the bottom of the inclined section before the formation pressure decays to $5.800 \mathrm{MPa}$.

\subsection{The diameter of the velocity string is 2.375 - 1.995 in.}

The wellhead pressure is 4MPa. At this time, the velocity string with the diameter of 2.375-1.995 in. is inserted into the bottom of the inclined section in Well $\mathrm{X} 2-1$, that is, the sounding depth is $3401.3 \mathrm{~m}$. The actual flow rate at this point is calculated to be $6.4374 \mathrm{~m} / \mathrm{s}$, the critical liquid carrying flow rate at the bottom of the inclined section is $2.2543 \mathrm{~m} / \mathrm{s}$, and the daily production is $91523.2 \mathrm{~m}^{3} / \mathrm{s}$. At this time, the actual flow rate is much higher than the critical flow rate, and the liquid carrying capacity of the gas well is enhanced and no effusion is produced.

Under the wellhead pressure of $4 \mathrm{MPa}$, the formation pressure is continuously reduced, and the actual flow rate and critical liquid carrying flow rate at $3401.3 \mathrm{~m}$ are calculated. Determine the downward time of 2.375-1.995 in. the velocity string, and calculate the gas production. The results are shown in Table 5:

Table 5. Downward entry timing of velocity string with diameter 2.375-1.995 in. at wellhead pressure $4 \mathrm{MPa}$.

\begin{tabular}{|c|c|c|c|c|}
\hline $\begin{array}{c}\text { Formation } \\
\text { pressure } \\
/ \mathrm{MPa}\end{array}$ & $\begin{array}{c}\text { Bottom } \\
\text { hole } \\
\text { pressure } \\
/ \mathrm{MPa}\end{array}$ & $\begin{array}{c}\text { Actual } \\
\text { flow } \\
\text { rate } \\
/(\mathrm{m} / \mathrm{s})\end{array}$ & $\begin{array}{c}\text { Critical } \\
\text { flow } \\
\text { rate } \\
/(\mathrm{m} / \mathrm{s})\end{array}$ & $\begin{array}{c}\text { Production } \\
/\left(\mathrm{m}^{3} / \mathrm{d}\right)\end{array}$ \\
\hline 8.100 & 7.049 & 6.4374 & 2.2542 & 91523.2 \\
\hline 7.100 & 6.246 & 5.2633 & 2.3979 & 66366.1 \\
\hline 6.100 & 5.561 & 3.2952 & 2.5442 & 37065.3 \\
\hline 6.000 & 5.505 & 3.3534 & 2.5573 & 33534 \\
\hline 5.900 & 5.452 & 2.7191 & 2.5699 & 29961.9 \\
\hline 5.800 & 5.401 & 2.4133 & 2.5822 & 26351.7 \\
\hline
\end{tabular}

The variation of actual flow rate and critical liquid carrying flow rate with formation pressure as shown in Fig. 5:

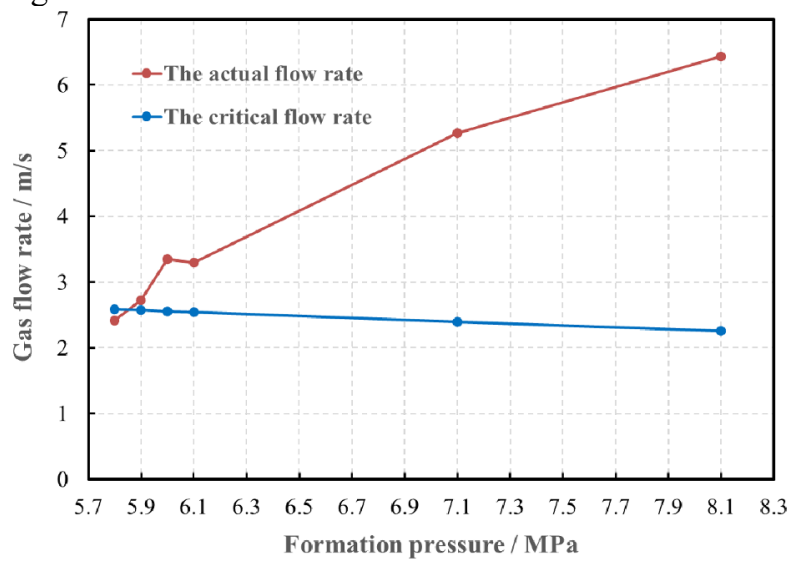

Fig. 5 The variation of the actual flow rate and critical flow rate after the diameter of 2.375-1.995 in. velocity string enters under the wellhead pressure of $4 \mathrm{MPa}$.

From Table 5 and Fig. 5, it can be seen that under the condition of wellhead pressure of $4 \mathrm{MPa}$, Well X2-1 downhole enters 2.375-1.995 in. velocity string to the bottom of the inclined well section. When the formation pressure is reduced to below $5.900 \mathrm{MPa}$, the gas flow rate will be lower than the critical flow rate, and the daily production is lower than $29961.9 \mathrm{~m}^{3} / \mathrm{d}$. At this time, the gas well begins to continue to accumulate fluid. Therefore, under the condition of wellhead pressure of 4 MPa, Well X2-1 should enter 2.375-1.995 in. velocity string to the bottom of the inclined section before the formation pressure decays to $5.900 \mathrm{MPa}$. 


\section{Conclusions}

In this paper, a method is designed to select the downward depth and timing of the velocity string in the case of highly deviated wells. The method is applied to Well X2-1 and Well X6-2 in PCOC, Ordos Basin, China. The specific results are as follows:

(1) The method flow of velocity string down-entry depth and down-entry timing identification for highly deviated horizontal wells is as follows: Firstly, the gas flow rate of vertical section and inclined section is calculated, and the gas flow rate of horizontal section is calculated by combining geological data and production data. Then the critical liquid carrying flow rate of the vertical section and inclined section is calculated by using the liquid carrying model of the gas well, to determine the depth of gas well effusion and determine the depth of velocity string. Finally, the diameter of the velocity string determined by the production data and the down-entry depth calculated previously is used to calculate the actual flow rate and the critical liquid carrying flow rate at the sounding depth combined with the wellhead pressure, to determine the down-entry time of the velocity string.

(2) For Well X6-2, the down-entry depth of the velocity string should be $3337.9 \mathrm{~m}$ at the bottom of the inclined section. Under the condition of wellhead pressure of 6.26 MPa, Well X6-2 should lower the 21.71 in. velocity string or 2.375-1.995 in. velocity string to the bottom of the inclined section before the formation pressure decays to $8.800 \mathrm{MPa}$.

(3) For Well X2-1, the down-entry depth of the velocity string should be $3401.3 \mathrm{~m}$ at the bottom of the inclined section. Under the condition of wellhead pressure of $4 \mathrm{MPa}$, Well X2-1 should lower the 2-1.71 in. velocity string to the bottom of the inclined section before formation pressure decays to $5.800 \mathrm{MPa}$, and lower the 2.375-1.995 in. velocity string to the bottom of the inclined section before formation pressure decays to $5.900 \mathrm{MPa}$.

\section{Acknowledgments}

Financial support for this research by the National Natural Science Foundation of China (No. 51874242) is gratefully acknowledged.

\section{References}

1. Chen M, Sun J, Gao E, et al. A Summary of Wellbore Fluid Accumulation and Drainage Gas Production Technology in Gas Wells[C]//IOP Conference Series: Earth and Environmental Science. IOP Publishing, 2021, 621(1): 012113.

2. Fanggang $X U$ E, Gangji $X$ U E. DRAINAGE GAS RECOVERY TECHNOLOGY[J]. Natural Gas Exploration and Development, 2014: 03.

3. Jianjun Z, Wei Z, Delin Y. Two Practical Techniques Prevent Gas Well Fluid Accumulation and Boost Production Rate [J]. FAULT-BLOCK OIL \& GAS FIELD, 2000, 3.

4. Matanović D, Gaurina-Međimurec N, Simon K. The Use of Coiled Tubing as a Velocity String[J]. Acta montanistica Slovaca, 9(4): 240-242.

5. Zhou J, Luo Y, Liu Y L. Research and application of velocity string drainage technology in horizontal wells of Daniudi[J]. China Petroleum Machinery, 2013, 41(12): 102-105.

6. Xie $\mathrm{Y}$, Wang $\mathrm{Y}, \mathrm{Xu} \mathrm{Y}$, et al. Velocity string drainage gas recovery technology in the application of Z21-22 well [J]. Petrochemical Industry Application, 2013, 6.

7. Zhao B, Xu X, Bai X. Discussion of the drainage gas recovery technology for low-cost velocity string[J]. China Petrol Mach, 2013, 41: 84-86.

8. Wuchao W U, Zhiping L I, Fengpeng L A I. Method to determine time of installing velocity string for horizontal well in tight gas reservoirs[J]. FaultBlock Oil \& Gas Field, 2015, 22(4): 522-525.

9. Binbin Z, Li L I, Xiaohong B A I. Research and test on water drainage gas recovery velocity string technology for horizontal well[J]. China Petroleum Machinery, 2018, 46(1): 88-91.

10. Hasan A R, Kabir C S. Determining bottomhole pressures in pumping wells[J]. Society of Petroleum Engineers Journal, 1985, 25(06): 823-838. 